of the tissue changes in them-for the fact that many of these cases have been published prematurely, and that in none of them is the nature of the enlargement recorded (in one at least it seems to have been malignant) - I think it may fairly be argued that the minority, small as it is, is much larger than it will be in the future.

In all but one case voluntary power of micturition was regained and the residual urine fell below two ounces. This was better than I had anticipated. It cannot, of course, be expected that removal of an obstruction is capable of regenerating muscular fibres that have been destroyed. It is well known that over-distension, the use of catheters, and long-continued inflammation can, each of them by itself, ruin the muscular power of the bladder, even in young men, so that it never recovers. It is not a matter for surprise, therefore, that such an event should occur in patients advanced in life when all these causes have been acting together upon the bladder for years past. The operation, however, is not to be blamed for the failure; that must be laid to the credit of the previous treatment which has allowed such a condition of things to come to pass and has encouraged it. The inflammation of the bladder, which was kept up by the obstruction at the neck, disappeared spontaneously in all but one. In this case the disease had lasted such a length of time that the walls of the bladder were covered with sacculi which could not be kept empty. In those in which the urine had been ammoniacal for some time, and in which the walls of the bladder were coated with a mixture of pus and triple phosphates, it was very interesting to watch the gradual disintegration and spontaneous discharge of the deposit as the urine regained its normal reaction. In some instances the masses that came away were of such a size as to cause a considerable amount of pain and inconvenience during their descent down the urethra. In the case of the patient who died upon the ninth day a calculus the presence of which had not been suspected during life, altiough the patient had been sounded by myself on several occasions and also by other surgeons, was found behind the middle lobe of the prostate. It had lain there in all probability for many years as it was of considerable size; and though it did not cause the patient so much pain as a movable calculus would have done there can be no doubt that it added very considerably to his misery, and that had he lived, and had the treatment by catheter been continued, he would never have experienced any real relief. As I have met with several instances of a very similar character-calculi lying unsuspected behind an enlarged prostate I always make a practice of specially examining for them in all cases in which the symptoms are either severe or of long duration. I am convinced that they are much more common in these cases than is usually believed.

There are two other points to which I wish to allude very briefly. Eighteen months ago I suggested to Professor Clarke of Glasgow the possibility that in some cases of enlargement of the prostate adequate relief might be ob. tained by the removal of one testis only. I have published elsewhere a case in which a large median outgrowth occurred in a man who had had one of his testicles destroyed shortly after birth, so that removal of one testicle will not prevent enlargement of the middle lobe at least. But where the enlargement does not involve the median portion, where the obstruction is caused simply by the enormous size of the dateral lobes (and such cases do occur and can be diagnosed beforehand), I suggested that unilateral orchotomy might suffice. Since then Mr. Manning of Salisbury has sent me full particulars of a case in which this method was adopted with perfect success. "In a few days the urine was passed in a fuller stream and the bladder seemed to regain its tone and empty itself. Before the operation the gland could be felt in the rectum as large as a small orange. One month after, if digital examination can be trusted, the right lobe was still enlarged, but not nearly to the same extent as before, but the left seemed to be of normal size; urine passed freely and was of a healthy character." Two months after: "The patient is stronger than he has been for years, and there is no urinary trouble of any sort or kind." One or two equally successful cases have been recorded in America (and a good many failures); but this is, I believe the first that has succeeded in Fingland. I should feel strongly disposed to advocate this in preference to the bilateral operation, or as a preliminary to it in case removal of one testis alone does not succeed, in all cases in which this condition is diagnosed beforehand.
The other point to which $\mathrm{I}$ wish to allude is the possibility of substituting for orchotomy double ligature and section of the vasa deferentia. If it could be shown that this answers as well, probably patients would agree to it more willingly, and certainly the operation would not entail so much risk. The evidence upon this point is rather conflicting, and an additional amount of confusion has been imported into the question by the fact that the influence of section of the vasa deferentia upon the prostate has not been clearly distinguished from that which it has upon the testes. The latter sometimes atrophy and sometimes they do not; the former appears to do so always, but to an extent that varies. Pavone ${ }^{6}$ and White ${ }^{7}$ have shown that this is the case with animals, and according to Pavone the involution of the gland is most marked in the central part; and a sufficient number of operations have been performed upon men to make the experiment (for such, of course, it is) justifiable. $\mathrm{Mr}$. Reginald Harrison ${ }^{8}$ was the first to divide the vasa deferentia in a case of enlarged prostate as a compromise, the patient wishing to be castrated. Six or seven years later he was alive and well. Tilden Brown ${ }^{9}$ ligatured both vasa deferentia under cocaine in a man seventy-two years of age with decided benefit, although at the time of reporting there were still three ounces of residual urine. Guyon ${ }^{10}$ has operated twice, and Lequen once, with a certain amount of improvement, the testicles remaining normal and the prostate diminishing a little in size, and Isnardi has also operated twice. In the first case ${ }^{11}$ the prostate almost disappeared and the bladder became so tolerant that the patient could rest at night for seven hours consecutively. In the second ${ }^{12}$ the result was almost as good, although the operation was performed only on the right side. The left testicle was atrophied and the left side of the prostate not enlarged.

These cases are of course not sufficiently numerous to allow of a definite answer being given to the question, but it must be admitted that they are most encouraging. According to Guyon, section of the vasa deferentia is not such a radical measure as orchotomy, and is chiefly indicated in that class of case in which what he calls "la prostatisme" is the most prominent feature.

Wimpole-street, $\mathrm{W}$.

\section{THE EYE AS A JOINT.}

BY E. STANMORE BISHOP, F.R.C.S. ENG., HONORARY SURGEON TO THE ANCOATS HOSPITAL.

ALTHOUGH the pendulum of fashion in treatment of synovitis inclines now mainly towards absolute rest as a sine qu$\hat{o}$ non in such cases, no one can see much of general practice without recognising that to the main balk of general practitioners the whole subject is a hazy one, the outlines of which are misty and undefined. Under the force of Hilton's teaching the profession for a long while preached rest; but it was a rest which was in nine times out of ten ill applied, and combined - fatally combined - with pressure over the inflamed area. Limbs were encased entirely in rigid plasterof-Paris dressings, or fixed to a board by bands which were carefully applied just where pressure could do the most harm. Moreover, the joints were often fixed at a bad angle, so that bad results often followed, which were wrongly attributed in the majority of instances to the undue duration of the rest. Then came the period when certain bone-setters totally upset the faith that was in the surgeon by a few cases - trumpeted until they became multiplied indefinitely in his mind-in which judicious, or sometimes lucky, movements succeeded in loosening a joint which was on the point of loosening itself (for a great point in all these cases was that they had previously consulted all the faculty); and once more to many of the profession joint inflammation and its sequelæ became mysteries, and their treatment a species of magic.

The correct instinct of the surgeon counselled him not to needlessly irritate a painful part, whilst the vague dread of leaving some highly important thing undone at some

II Policlinico, June 1st, 1895.

Annals of Surgery, July, 1895, p. 45

Brit. Med. Jour., Sept. 23rd, 1893.

New York Medical Journal, Nov. 30th, 1895. French Surgical Congress, 1896.

11 Centralblatt für Chirurgie, 1895, No. 28, p. 657. 
unknown critical moment harassed him with never-ending uneasiness. There were never wanting counsellors who impressed upon him the fact that another medical man had just lost a patient because, having kept a limb of the latter tou long at rest, the joint had become stiff and the patient utterly dissatisfied, and that had it not been for the services of Mr. Blank, the eminent bone-setter, who cleverly broke down several adhesions, the use of the limb would have been entirely lost. Naturally the surgeon came to look upon adhesions within the joint as the rock upon which his treatment was bound to split, and, determining to be beforehand with Mr. Blank, decided to do the breaking down himself. But when should this be done? Clearly it must in any case be performed before the patient had disappeared; and so presently the surgeon, being doubtful of the exact condition present, the date of the wrenching began to depend more upon the appearance of any sign of impatience on the part of the sufferer than upon anything else. And now a strange thing was noticed. However early this wrenching might be done adhesions were always present. The surgeon felt them give, admiring spectators heard them crack, and after they had cracked, under chloroform, the joint moved easily in every direction. At first surgeon, patient, and friends congratulated themselves and each other on the skill displayed by the practitioner. But a stranger thing still corced itself upon their unwilling attention. When the patient recovered from the anæsthetic the joint was in nine cases out of ten stiffer than before and very painful. The pain was pooh-poohed - that would "soon wear off." The joint was now free and the oint must be kept so. There must be no more adhesions. Movements of various kinds, the carrying of weights, and persistent plucky attempts on the patient's part were absolute duties, and must be persisted in at all costs. When the joint did not improve, as it generally did not, this was evidence of reprehensible laziness and cowardice on the part of the patient, who evidently was not carrying out the orders of his surgeon, and who was sacrificing the whole future usefulness of his limb to a pitiful shrinking from slight pain. No sympathy could be felt for such a man, and if he had a stiff arm or leg for the rest of his life that was clearly his fault alone. Sometimes a miserable doubt assailed the surgeon: "Is it possible that I did not thoroughly break all the adhesions down? May not there possibly be one small one which was overlooked at the time, and which, though then so small as not to be detectable, has yet the power to spoil all my other work? Let us once more anæsthetise the man and see." And then, most marvellous of all, however short a time had elapsed since the last wrenching there were all the old adhesions back again, and they all had to be broken down again as if they had nerer been touched. Was it possible that such a crop should have grown to full heiglit in so short a time? Evidently this man was a fraud; he could never have moved this joint at all; primary union must have taken place directly and within a week or two; the scar union was so tough as to require great force once more to separate it. Very, very occasionally a fear that perhaps after all this was not the right track to follow was felt, but it was speedily put out of court by a flaming report of another marvellous cure by Mr. Blank in some case which had been stiff for many months or years owing to the culpable misuse of rest by his previous attendants and their ignorance of the cabalistic movements practised by that marvellous gentleman. And then certain books appeared, written by wellknown members of the medical profession, in which such movements were mentioned with laudation, certain general directions given as to how they were to be applied, and the use of rest was spoken of as undoubtedly advisable, with limitations, which limitations were very hazily indicated, antil the unfortunate practitioner, who for his sins had been cursed with an inflamed joint to treat, was in a worse fog than ever, yet keenly conscious that he must do something, but as to what or how it was to be done he was utterly and miserably doubtful. How often must the wish have been expressed, "If only now I could look inside and see what is going on, see whether there really are adhesions, and where whey are situated, how much clearer would be my idea of what I am doing and what remains for me to do." In this state of uncertainty has it ever occurred to anyone that nature herself has, as if purposely, left open one joint to inspection, so that not only can the surgeon see the normal state of it, but he can also see for himself the changes which take place during its inflammation, watch its various stages, examine and note their results, and-most important of allsee the effect of various modes of treatment, enabling him to apply the knowledge thus gained to the treatment of those joints which she has closed, and in which these same processes go on therefore unseen?

Such a joint is the eye. This is, if one thinks of it, a true ball-and-socket joint. The ball is modified certainly for a special purpose, but its cornea is, after all, only a translucent form of cartilage; its socket, the upper lid, contains also a layer of cartilage, and both are lined by a serous membrane in every respect comparable to the synovial membrane which lines every other movable joint in the body. In conjunctivitis, the synovitis of the eye, there is a visible process which can be watched. In the first or acute stage note the efforts nature makes to procure rest to the joint. Irritation in the conjunctiva sets up a tonic contraction of the orbicularis and other muscles which closes the eye. Do ophthalmic surgeons therefore dread the occurrence of adhesions between the ball and lid; or do they during this acute stage produce forcible movements of the ball upon its socket, or vice versî, with a view to prevent these? Surely, in such cases the first and main object is rest in a darkened room so that as little friction as possible shall occur between the two; and anyone who violently wrenched the socket backwards and forwards over the eye because he feared the two might adhere would only precipitate the very occurrence he feared by denuding the surfaces of their softened epithelium, and leaving two raw surfaces, which then might unite. Rest above all other things is the sine quâ non. True, solutions of cocaine or atropine are often used, but with what purpose but that of increasing the physiological rest? The iris is dilated and thus kept in its most restful condition. Adhesions of it are feared if, left to itself, it is allowed to make the multitudinous contractions and dilatations of which it is capable under the influence of light and accommodation. but such adhesions are infinitely rare if the organ is kept immovable in the position of rest. And if this rest to the eye is thoroughly and completely carried out from the first the percentage of eyes which absolutely recover from a condition of simple conjunctivitis is almost cent. per cent. And if this is true of simple conjunctivitis and simple synovitis, is it not equally true of the rheumatic, gouty, gonorrhœal, and other varieties of the same condition? The prognosis of the ultimate result will be modified, and gravely modified, by every departure from the typical simple condition; but will the surgeon improve such prognosis by any deviation from the fundamental and essential treatment? Will a gonorrhœal conjunctiritis be improved by incessant rubbing of the inflamed surfaces together or by an intermittent forcible wrenching of the lids? In an ulcer of the cormea perforation may occur. Will this be rendered less likely to happenindeed, will it not be more likely to precipitate its occurrence-by rubbing the lid violently over the ulcerated edges once a week or once a fortnight or by encouraging the patient to work his eye about so many times a day? Whilst in such graver conditions as exist in gouty, rheumatic, or gonorrhoeal arthritis the prospects in any case of a return to the normal are less than they would be in simple synovitis, such prospects are given their best possible chance by absolute rest during the acute stage, and movement then can only intensify the pathological change present and decrease the likelihood of a satisfactory result. Why should the surgeon consider it a slight upon his professional skill if such a case recovers with a permanent disability? It is in the nature of things that this must be so. It is the disease which inevitably tends to produce certain lesions which are irremediable; but he must see to it that such lesions are only those which are inevitable, and not those intensified or produced by his own over-zealous but ill-instructed efforts.

When should this rest be given up ? Not, surely, until the acute stage is absolutely past. What would be thought of the ophthalmic surgeon who rested such an eye for half this stage, and in the middle of it started to violently wrench the lid, the socket, up and down for fear of adlicsions? He would bring back all the acute symptoms which were gradually dying away and indefinitely prolong the period of their existence. How does he know when conjunctivitis has ceased? Doubtless by the appearance of the conjunctiva. But is there no other symptom present in this which is also present in other joints and which he can utilise in his judgment of them? During the acute stage the lids are spasmodically closed, and if the surgeon wishes to open them for the purpose of introducing cocaine, \&c. - which, be it noted, he does with the extremest gentleness-he finds himself opposed with all the force of the orbicularis. When inflammation has gone there is no 
such spasm. The difficulty then is to keep the eyes closed, and any, even the slightest, effort to open them is easily performed. During the acute stage of inflammation of any other joint there is encountered the same muscular contraction, and in the same way when all inflammation has disappeared from it the muscles which before were tonically contracted relax, and the difficulty is not to move the joint but by any means to keep it still. And it is by this sign, and by this sign alone, that the surgeon can be sure that it is safe now to use passive motion, if, indeed, in a joint which has suffered from simple synovitis and has been so treated passive motion is ever really required.

All treatment, then, of closed joints, as of the one open to observation, during the acute stage of simple inflammation should be directed towards the perfecting of nature's own remedy-that of rest. As he knows that of all the muscles around any joint, all of which are contracting in this way, the flexors will sooner or later obtain the advantage, the medical man arranges his apparatus so as to maintain an equilibrium and prevent any deformity which might arise by their excessive action. As he knows that muscles, though strong, are capable of becoming tired, and, especially when sleep overpowers the patient, of being momentarily relaxed, so permitting of slight movements in, and jars to, the inflamed surfaces, he assists their action by rigid appliances which shall supplement or, if necessary, be substitutes for them. But all this has been said, and said much better, by Hugh Owen Thomas and his successor, Mr. Robert Jones, to whose works, which are worth most careful study, I would refer all interested in this subject. My only object is to point out what I believe has not been previously noted-the presence before the surgeon's eyes of an open joint in which he may verify for himself the truth or otherwise of various doctrines with reference to the treatment of those other closed joints about which so much mystery has been made, and as to the exact condition of which so much doubt and paralysing uncertainty have existed, and still exist, in the minds of many surgeons.

Manchester.

\section{CASE OF REMOVAL OF THE SCAPULA AND UPPER EXTREMITY FOR SARCOMA.}

BY G. C. HALL, F.R.C.S.,

SORGEON-LIEDTENANT-COLONEL, INDIAN MEDICAL SERVICE, BENGAT.

THE patient, a beggar, had been wandering about the country carrying an enormous tumour the surface of which

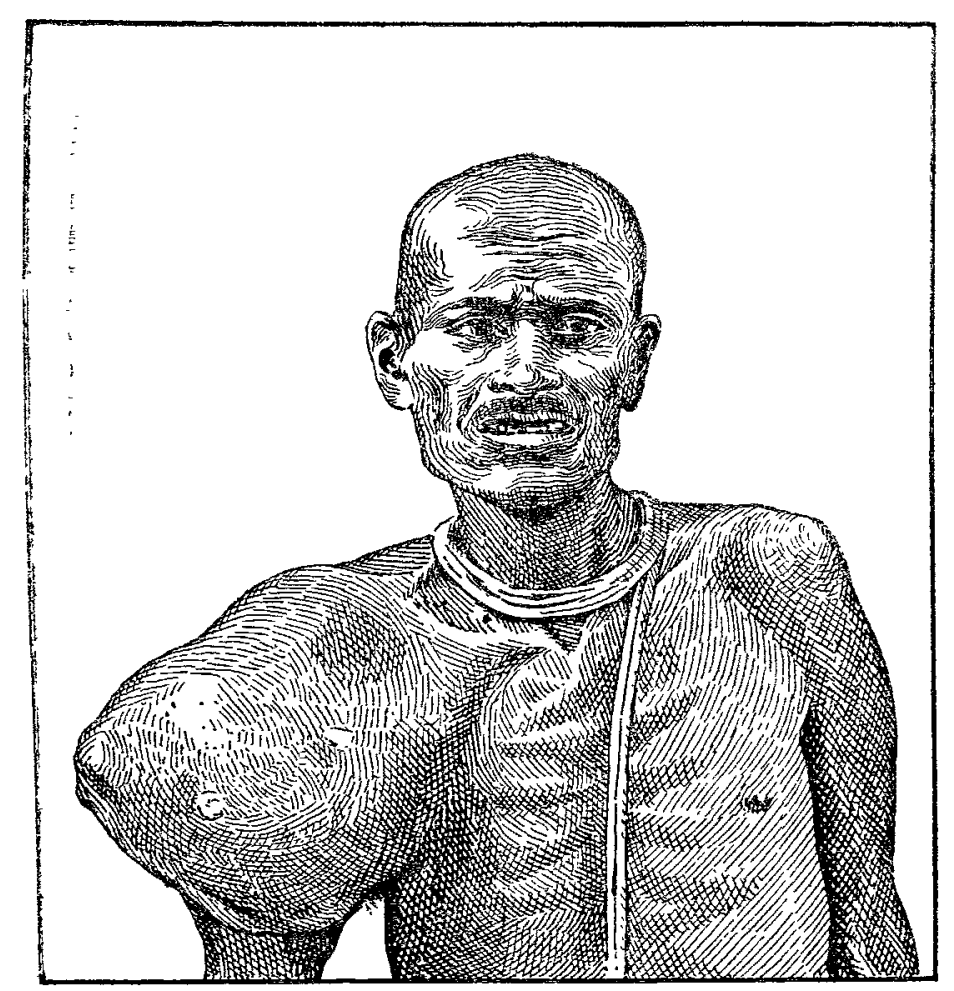

was ulcerated in places, on which numerous flies found a feeding ground. He had been rejected as a hospital case by numerous dispensary assistant surgeons and others, and had determined to take his life by drowning himself in the River Jumna. I therefore thought that he should at least have the chance offered by surgical intervention, and I decided to try to remove the tumour. His physical condition was as bad as it could be. I chloroformed him carefully, and began by making a posterior skin flap, securing the vessels en route, and loosened the attacliment of the scapula. I then attacke

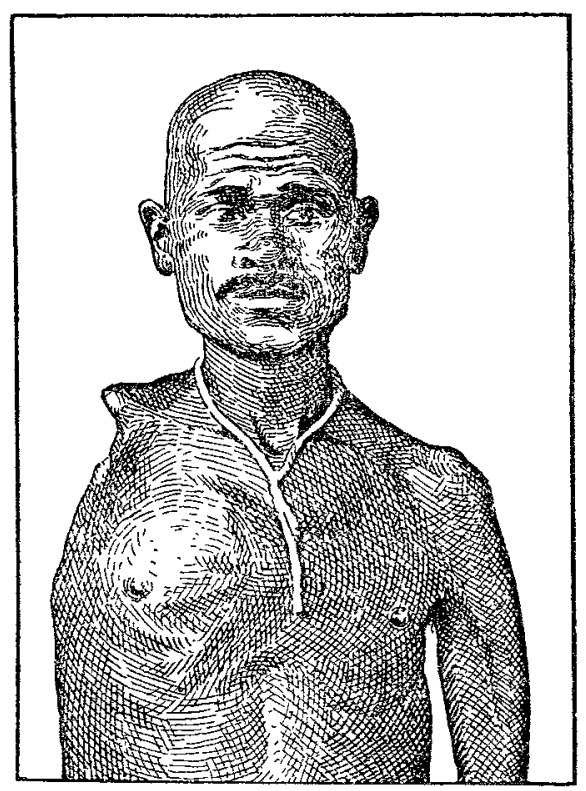

the front and tied the subclavian artery and found that the tumour had no attachment to the thorax, as had been thought to be the case. I then disarticulated the clavicle from the scapula, and removed the limb. He had no bad symptoms; he made a rapid recovery, and went to bathe in the Ganges and thank his special deity for favour vouch-

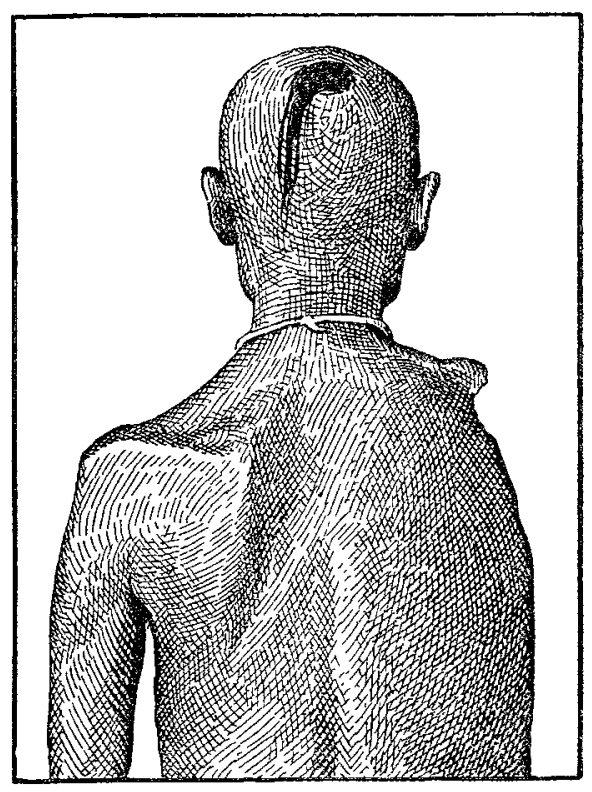

safed to him, having his mind firmly made up that as $I$ had removed his arm I would have to support him for the rest of his life. The gratitude of the Indian beggar is well known. The illustrations, which are from photographs, represent the condition of the patient before and after the operation.

Allahabad, India.

\section{THE INFLUENCE OF INHERITANCE ON THE TENDENCY TO HAVE TWINS.}

BY R. A. BREMNER, L.R.C.P. LoNo., M.R.C.S. ENG.

IN continuation of the recent articles on the tendency to twin births ${ }^{1}$ I send the following family history, which is vouched for by more than one of the relatives. I attended the mother of the last pair of twins, herself one of twins. 